\title{
Prophylactic HIPEC with radical D2 gastrectomy improves survival and peritoneal recurrence rates for locally advanced gastric cancer: personal experience from a randomized case control study
}

Maneesh Kumarsing Beeharry, Zheng-Lun Zhu, Wen-Tao Liu, Xue-Xin Yao*, Min Yan and Zheng-Gang Zhu*

\begin{abstract}
Background: To investigate the implications of prophylactic intraoperative Hyperthermic Intraperitoneal Chemotherapy (HIPEC) with D2 radical gastrectomy for locally advanced Gastric Cancer (AGC) in a randomized case control study.

Method: Eighty consecutive patients with locally AGC were randomly separated into 2 groups: HIPEC group (Curative Resection + intraoperative HIPEC with cisplatin $50 \mathrm{mg} / \mathrm{m}^{2}$ at $42.0 \pm 1.0^{\circ} \mathrm{C}$ for $60 \mathrm{~min}$ ) and Control group (Curative Resection only). Intraoperative and post-operative events, clinical recovery, morbidity and the disease-free survival (DFS) rates were closely monitored.

Results: Faster recovery of bowel function ( $43 \pm 5 \mathrm{~h}$ vs $68 \pm 7, P<0.05)$ and shorter postoperative stay ( $8 \mathrm{~d}$ vs $14 \mathrm{~d}, P<$ 0.05) were noted in the HIPEC group. Among the 40 HIPEC group patients, the highest intracranial temperature recorded during the procedure was $38.2^{\circ} \mathrm{C}$ but the patient made an eventless recovery. Mild renal dysfunction, hyperbilirubinemia and mild liver dysfunction were recorded in the HIPEC group but their incidences were found to be statistically insignificant when compared with the control group $(P>0.05)$. The 3 year DFS rate analysis showed that the prophylactic HIPEC group had a higher DFS rate (93\% vs 65\%, $P=0.0054)$. The peritoneal recurrence rate was lower in the HIPEC group (3\% vs 23\%, $P<0.05)$.
\end{abstract}

Conclusion: Prophylactic HIPEC with radical D2 Gastrectomy improves survival and peritoneal recurrence rates for AGC with favorable post-operative recovery at low and acceptable morbidity.

Keywords: Advanced gastric Cancer, HIPEC, Cisplatin, Procedure morbidity, DFS

\section{Background}

Gastric cancer (GC), one of the main leading causes of cancer-related mortality worldwide [1], is associated with a relatively high risk of peritoneal carcinomatosis (PC) with a prevalence rate of $5-20 \%$, as a result of which around $50 \%$ of patients with potentially curable advanced gastric cancer (AGC) die from cancer recurrence

\footnotetext{
*Correspondence: yaoxuexin2017@163.com; zzg1954@hotmail.com Department of Surgery, Ruijin Hospital affiliated Shanghai Jiao Tong University School of Medicine, Shanghai 200025, China
}

in the peritoneum [2]. Nevertheless, 15 to $50 \%$ of AGC patients with serosal involvement present peritoneal dissemination at surgical exploration [3] and such cases have been associated with poor survival as shown by many phase III trials that reported median survival ranging from 1 to 13.8 months [3-8] and no survivor at 5 years $[9,10]$.

In a study performed on $1108 \mathrm{GC}$ patients undergoing radical D2 gastrectomy, almost $50 \%$ of the patients had tumor recurrence, with $15.5 \%$ manifesting metachronous PC after a median time of 17.7 months post-surgery and 
upon further investigation, the degree of serosal involvement, extent of nodal metastasis and tumor pathological subtype (signet cell or undifferentiated carcinoma) were found to be risk factors leading to disease progression to PC $[11,12]$. In the Japanese General Rules of Gastric Cancer Treatment, PC is separated into two categories: $\mathrm{P} 0 / \mathrm{Cy} 1$ and $\mathrm{P} 1$ [13]; $\mathrm{P} 0 / \mathrm{Cy} 1$ indicating positive peritoneal wash cytology without macroscopic PC while P1 indicates the macroscopic PC with or without positive peritoneal cytology and it has been shown that the prognosis of P0/Cy1 GC is similar to P1 GC [14]. Because of the limited efficacy of systemic chemotherapy to control PC, other treatment strategies including regional approaches have been explored and hence, Hyperthermic intra-peritoneal chemotherapy (HIPEC) has shown to effectively control PC from ovarian or mucinous appendiceal cancer [15-17]. A meta-analysis based on the evaluation of 280 studies analyzing the implications of HIPEC for GC patients with serosal invasion indicated that HIPEC could potentially allow a better prognosis in patients at acceptable rate of complications [18].

Our personal experience shows that HIPEC shows promise in the management of AGC as prophylaxis to peritoneal recurrence [19]. However, despite the supposed high efficacy of intraoperative HIPEC combined with radical resection, this multimodal approach has yet not been considered as a routine practice for AGC clinical management and this might be a result of the high procedure related morbidity. The early attempt from Fujimura et al. reported a morbidity of $50 \%$ and a reoperation rate of $33.3 \%$ [20]. Nevertheless, later studies were more optimistic with morbidity rates ranging from 9.6 to $55.6 \%$, and mortality rates of 0 to $14.3 \%$ [21]. In a meta-analysis of randomized and high quality nonrandomized studies investigating the role of HIPEC in the GC [22], Desiderio et al investigated a total of 2520 cases and for the GC patients without PC, the overall survival rates between the HIPEC and control groups at 3 or 5 years resulted in favor of the HIPEC group $(R R=$ $0.82, P=0.01)$. However, HIPEC was associated with significantly higher risk of complications for both patients with $\mathrm{PC}(\mathrm{RR}=2.15, P<0.01)$ and without $(\mathrm{RR}=2.17$, $P<0.01$ ) [23]. This increased risk in the HIPEC group was related to systemic drugs toxicity while anastomotic leakage rates were found to be similar between groups.

Hence, in this randomized case-control study, we have investigated the feasibility and morbidity of intraoperative HIPEC as prophylaxis against PC in AGC patients and compared the survival rates in a small cohort.

\section{Methods}

\section{Patients selection}

Between December 2014 and June 2015, consecutive AGC patients were carefully screened and 80 GC patients conforming with the following criteria were included for the study: (1) aged between 18 and 76 years old; (2) Primary GC; (3) Preoperative staging (Computed Tomography or endoscopic ultrasonography) revealing lesion(s) infiltrating the sub-serosal layers and above ( $\mathrm{T}$ staging $\geq \mathrm{T} 3$ ); (4) Karnofsky performance status (KPS) > 50; (5) Peripheral blood white blood cells (WBC) count $\geq 3500 / \mathrm{mm}^{3}$, platelet count (PLT) $\geq 80,000 / \mathrm{mm}^{3}$ and hemoglobin count $(\mathrm{Hb}) \geq 90 \mathrm{~g} / \mathrm{L}$; (4) Normal liver function, with bilirubin $\leq 2$ times the upper limit of normal (ULN), and aspartate aminotransferase (AST) and alanine aminotransferase (ALT) $\leq 2 \times U L N$; (5) Normal renal function, with serum creatinine $(\mathrm{SCr}) \leq 1.5 \mathrm{mg} / \mathrm{dl}$; (6) Full cardiac and pulmonary assessment without obvious surgery contra-indications. Patients with positive cytology during the laparoscopic examination were excluded from the study.

Patients conforming to the requirements signed informed consent. The study was approved by the institutional review board and the ethics committee of Shanghai Jiao Tong University School of Medicine affiliated Shanghai Ruijin Hospital.

\section{Randomization}

Pre-printed group allocation chits were sealed in 80 envelopes which would randomly separate 80 consecutive patients into 2 groups: the HIPEC group $(n=40)$ and the Control group $(n=40)$ whereby the HIPEC group would include patients who would undergo Radical Surgery (RS) followed by intraoperative HIPEC while the Control group would only undergo RS. Randomization was performed on the day of surgery just before the operation would start.

All RS + HIPEC procedures were performed by a designated team of surgeons. After anesthesia, laparoscopic exploration with primary peritoneal lavage cytology was conducted to rule out occult peritoneal dissemination. All of the subjects underwent standardized radical gastrectomy with D2 lymphadenectomy. After anastomosis, the panel of trained and experienced surgeons with a designated anesthesiologist would conduct the intraoperative HIPEC using the RanD Performer ${ }^{\circ}$ HT perfusion device (RanD Co. Ltd., Italy). The open coliseum technique HIPEC was adopted for optimal thermal homogeneity and spatial diffusion with $50 \mathrm{mg}$ of cisplatin (CDDP) per liter of saline perfusate, maintained at $42.0 \pm 1.0^{\circ} \mathrm{C}$. The perfusion rate was controlled between 600 and $1000 \mathrm{~mL} / \mathrm{min}$ and total perfusion time was $60 \mathrm{mins}$.

During the procedure, 6 temperature probes placed at the inlet, outlet, upper right, upper left, lower right and lower left abdomen were used to dynamically monitor temperature during the procedure. 2 other probes were used by the anesthesiologists to allow continuous monitoring of the patient's arterial blood and intracranial 
temperature by using an intranasal probe. For statistical purposes, temperatures were tabulated at $10 \mathrm{mins}$ intervals during the procedure. In case of dangerous hyperthermia, including body, intraperitoneal and intracranial temperatures exceeding $44^{\circ} \mathrm{C}$, bleeding and unstable vitals, the whole process would be stopped.

\section{Parameters and post-operative follow-up}

The basic clinico-physiological parameters such as temperature, blood pressure, respiration rate and heart rate were monitored on a daily basis with blood routine, liver and renal functions and electrolytes examinations repeated at days 1,3 and 7 . Other clinical parameters involved the time of nasogastric extubation, number of hours to recovery of bowel function (flatus or bowel movement), pain management, incidence of adverse effects (AE) or severe adverse effects (SAE) such as peritonitis, myelosuppression, anastomotic leak, bowel obstruction, intestinal necrosis, renal or hepatic dysfunctions, jaundice, loss of hair, abdominal distress, surgical wound dehiscence and the duration of postoperative stay of subject. The data recording was performed by a group of nurses blinded to the randomization result.

\section{Post-operative follow-up and end-points}

The primary endpoint was 3 years post-surgery. Inhospital perioperative complications were studied as secondary endpoints. Postoperative complications were classified based on the therapy-oriented severity grading system (TOSGS) and NCI Common Terminology Criteria (CTC) for Adverse Events version 4.0. Postoperative morbidity was analyzed according to the DindoClavien classification for surgical complications [24]. The survival study involved comparison of the diseasefree survival (DFS) in both groups. The patients from both groups were administered to 6 regimens of standard dosage of the XELOX regimen starting within 1 month after surgery (Regimen: Oxaliplacin $130 \mathrm{mg} / \mathrm{m}^{2}$ ivgtt $\mathrm{d} 1$ + Xeloda $1500 \mathrm{mg} / \mathrm{m}^{2}$ bid po $\mathrm{d} 1-15$, Q3W) .

\section{Statistical analysis}

All data were systematically collected to establish a comprehensive database of clinical records, surgical and pathology reports, image examination and laboratory reports, and follow-up records. The data were analyzed by SPSS software for windows, version 19.0 (SPSS Inc., Chicago, IL, USA). The Kaplan-Meier survival curve was plotted for survival analysis and the log rank test was utilized to identify difference between curves. A two-sided $P<0.05$ was considered as statistically significant.

\section{Results}

Clinico-pathologic Characteristics of the subjects Between December 2014 and June 2015, 94 consecutive patients conforming to the requirements of the study were initially included in the study. However, 14 patients were excluded from the study due to positive cytology after the laparoscopic exploration (see Fig. 1 for the study consort diagram).

There were 46 male and 34 female patients with a mean age of 59 years for the HIPEC group and 58 years for the control group $(P>0.05)$. The median KPS was over $80 \%$ for all patients (Table 1). All the physiological and biochemical blood parameters to be investigated in the patients at the various time-points were weighed and recorded at baseline and no differences were found, suggesting that the model was well-balanced.

There was no significant difference in the histology of the lesions, the surgical procedure (distal or total gastrectomy), rate of lymph node metastasis or post-operative TNM staging of the subjects (Table 2).

\section{Safety implications of HIPEC Monitoring of the different temperature probes during HIPEC revealed no significant fluctuations in the intracranial and peripheral blood temperatures}

During the 60 mins HIPEC circulation time, the blood ( $\left.\mathrm{T}_{\text {blood }}\right)$ and intracranial $\left(\mathrm{T}_{\text {intracranial }}\right)$ temperatures were also recorded at $10 \mathrm{~min}$ intervals and the results are shown in Table 3. There was no significant statistical difference between the blood and intracranial temperatures at all time-intervals when the intraperitoneal temperature was maintained at $42.0 \pm 1.0^{\circ} \mathrm{C}$. maximum blood and intracranial temperature was $38.1{ }^{\circ} \mathrm{C}$ both recorded at 50 mins in 1 patient but the latter made an eventless recovery from surgery.

\section{The 7 days post-operative temperature monitoring showed that there was no fever due to the intraoperative hyperthermia}

As shown in Table 4, there was a significant difference in the temperatures recorded on days 1 and 2 post-op: the temperature of the control group was significantly higher than the HIPEC group $\left(37.7\right.$ versus $36.8^{\circ} \mathrm{C}$ on Day 1 and 37.2 versus $36.7^{\circ} \mathrm{C}$ on Day 2). No postoperative fever was recorded in the HIPEC group while in the control group, temperatures higher than $38.0^{\circ} \mathrm{C}$ were recorded in 2 patients on day 1 and 15 patients on day 2. However, there was no high temperature recorded from days 3 to $7(P>0.05)$. The patients presenting with temperatures higher than $38.0^{\circ} \mathrm{C}$ had slightly elevated white blood counts but without any complaint of any related discomfort.

The patient who had blood and intracranial temperatures exceeding $38^{\circ} \mathrm{C}$ during the HIPEC procedure had a maximum temperature of $37.4^{\circ} \mathrm{C}$ on day 1 and a mean of $36.94{ }^{\circ} \mathrm{C}$ over the post-operative week. 
Table 1 Clinicopathological characteristics of the subjects

\begin{tabular}{|c|c|c|c|}
\hline Characteristics & HIPEC Group $(n=40)$ & Control group $(n=40)$ & $P$ value \\
\hline \multicolumn{4}{|l|}{$\operatorname{Sex}(n, \%)$} \\
\hline Male & $23(57.5)$ & $23(57.5)$ & \multirow[t]{2}{*}{1} \\
\hline Female & $17(42.5)$ & $17(42.5)$ & \\
\hline Mean age (years, range) & $59 \pm 10(23-72)$ & $58 \pm 10(36-74)$ & 0.95 \\
\hline Mean KPS score (range) & $85 \pm 6(70-90)$ & $85 \pm 6(70-90)$ & 0.979 \\
\hline \multicolumn{4}{|l|}{ Histopathology (n, \%) } \\
\hline Adenocarcinoma (poor or moderately differentiated) (n, \%) & $25(62.5)$ & $26(65)$ & \multirow[t]{2}{*}{1} \\
\hline Adenocarcinoma (Mucinous, signet cell or other type) (n, \%) & $15\{37.5)$ & $14(35)$ & \\
\hline \multicolumn{4}{|l|}{ Pre-operative Blood physiological and biochemical Parameters } \\
\hline WBC $\left(10^{9} / L\right)$ & $5.7 \pm 1.4$ & $5.7 \pm 1.4$ & 0.785 \\
\hline $\operatorname{RBC}\left(10^{12} / L\right)$ & $4.2 \pm 0.6$ & $4.3 \pm 0.5$ & 0.78 \\
\hline $\mathrm{Hb}(\mathrm{g} / \mathrm{L})$ & $130 \pm 14$ & $127 \pm 20$ & 0.339 \\
\hline Alb (g/L) & $40 \pm 5$ & $39 \pm 4$ & 0.152 \\
\hline AST (IU/L) & $20.4 \pm 6.3$ & $19.4 \pm 8.1$ & 0.094 \\
\hline $\mathrm{ALT}(\mathrm{IU} / \mathrm{L})$ & $20.3 \pm 9.3$ & $17.1 \pm 8.2$ & 0.854 \\
\hline TB (umol/L) & $13.2 \pm 4.6$ & $12.9 \pm 3.9$ & 0.456 \\
\hline DB (umol/L) & $2.2 \pm 1.0$ & $2.3 \pm 0.08$ & 0.626 \\
\hline $\mathrm{SCr}(\mathrm{umol} / \mathrm{L})$ & $73.5 \pm 15.2$ & $76.8 \pm 27.3$ & 0.134 \\
\hline $\mathrm{K}^{+}(\mathrm{mmol} / \mathrm{L})$ & $3.95 \pm 0.45$ & $3.84 \pm 0.39$ & 0.456 \\
\hline $\mathrm{Na}^{+}(\mathrm{mmol} / \mathrm{L})$ & $141 \pm 5$ & $140 \pm 4$ & 0.334 \\
\hline
\end{tabular}

KPS Karnofsky Performance Score, WBC White Blood Cell Count, RBC Red Blood Cell Count, Hb Hemoglobin, Alb Albumin, AST Aspartate Aminotransferase, ALT Alanine transaminase, TB Total Bilirubin, DB Direct Bilirubin, $\mathrm{SCr}$ Serum Creatinine, $\mathrm{K}^{+}$Potassium lon, $\mathrm{Na}^{+}$Sodium lon, $\mathrm{CT3}$ clinical evidence of sub-serosal invasion, cT4 clinical evidence of serosal invasion

Overall, the hyperthermic activities during the HIPEC procedure did not cause hyperthermia or hypothermia in the patients. No patient from the HIPEC group manifested post-operative fever or any complication that could be related to the intraoperative hyperthermia.

\section{Post-operative morbidity and mortality}

With all post-operative morbidity assessed according to CTCAE v4.0, of the 40 patients, adverse-effects (AE) were recorded in 14 patients, 3 in the HIPEC group (7.5\%) and 11 in the control group (15\%). There was no 30-day

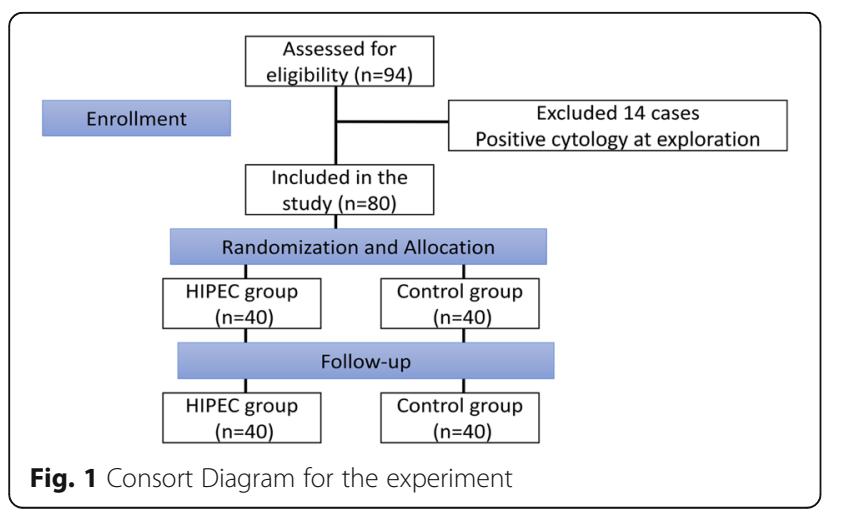

mortality in both groups. Mild neutropenia was recorded on post-op day 1 in 3 patients, 1 in the HIPEC group and 2 in the Control group. However, without specific therapy, the blood panels of the patients were normal on day 3 and stayed so on days 7 and 30. Mild bowel obstruction or intestinal ileus was noted in 1 patient from the Control group but the situation resolved after 2 days of conservative therapy. Mild renal toxicity was recorded in 2 patients, one from each group but renal function had resolved by day 7 without prompting for any further specific intervention. Mild abnormalities in liver function were recorded in 2 patients from the Control group which eventually resolved after courses of immediate hepatoprotective treatment. Mild hyperbilirubinemia was noted in 1 HIPEC case and 2 control cases and the patients were treated conservatively and the total bilirubin count was back to normal in both cases at day 7. 1 case from the control group manifested with surgical wound dehiscence with localized infection. Nevertheless, there was no incidence of post-operative bleeding, gastroparesis, HIPECrelated peritonitis, anastomotic leak, intestinal necrosis, diarrhea or allergic reactions in both groups (Table 5).

When the cases with complications were independently compared with the corresponding incidence in 
Table 2 Surgical procedures and pathological characteristics of the subjects

\begin{tabular}{|c|c|c|c|}
\hline Characteristics & $\begin{array}{l}\text { HIPEC Group } \\
(n=40)\end{array}$ & $\begin{array}{l}\text { Control group } \\
(n=40)\end{array}$ & $\begin{array}{l}P \\
\text { value }\end{array}$ \\
\hline \multicolumn{4}{|l|}{ Surgical Procedures } \\
\hline Total Gastrectomy & $13(32.5)$ & $17(42.5)$ & \multirow[t]{2}{*}{0.489} \\
\hline Distal Gastrectomy & $27(67.5)$ & $23(57.5)$ & \\
\hline \multicolumn{4}{|l|}{$\begin{array}{l}\text { Postoperative T Staging: } \\
\text { pT3 versus pT4a }\end{array}$} \\
\hline pT3 & 2 & 2 & \multirow[t]{2}{*}{1} \\
\hline pT4a & 38 & 38 & \\
\hline \multicolumn{4}{|l|}{ Postoperative pN Staging } \\
\hline No & 3 & 9 & \multirow[t]{5}{*}{0.362} \\
\hline N1 & 7 & 8 & \\
\hline N2 & 10 & 9 & \\
\hline N3a & 10 & 8 & \\
\hline $\mathrm{N} 3 \mathrm{~b}$ & 10 & 6 & \\
\hline $\begin{array}{l}\text { Rate of Lymph Node } \\
\text { Metastasis (\%) }\end{array}$ & $27.8 \pm 23.3$ & $33.1 \pm 28.1$ & 0.06 \\
\hline \multicolumn{4}{|l|}{$\begin{array}{l}\text { Postoperative pTNM } \\
\text { Staging }\end{array}$} \\
\hline$\| \mathrm{A}$ & 0 & 1 & \multirow[t]{5}{*}{0.242} \\
\hline$\| \mathrm{B}$ & 2 & 8 & \\
\hline$\| \mathrm{A}$ & 8 & 7 & \\
\hline$\| I \mathrm{~B}$ & 11 & 10 & \\
\hline$\| I I C$ & 19 & 14 & \\
\hline
\end{tabular}

the Control group using Pearson Chi Square test (Table 6), it was found that there was no statistically significant difference between the 2 groups, implying that the post-operative complications recorded in the HIPEC group was not related to the HIPEC procedure itself $(P=0.556)$.

\section{Post-operative clinical management parameters}

The median time to nasogastric tube removal was 1 day in both groups $(P>0.05)$. Interestingly, the time to

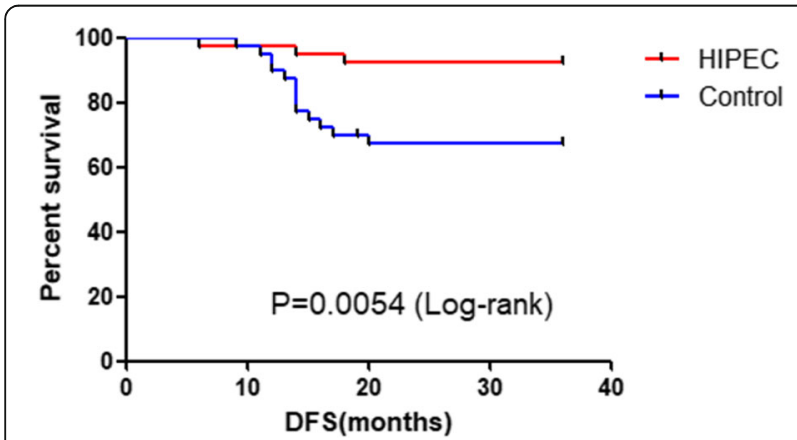

Fig. 2 Short-term Disease free survival (DFS) analysis of the HIPEC versus Control Group recovery of bowel function was shorter in the HIPEC group (42.9 versus $67.8 \mathrm{~h}, P<0.05)$, and subsequently the time to liquid diet was shorter in the HIPEC group (3.03 versus 4.02 days, $P<0.05$ ). The time to surgical sutures removal was 7 days in both groups $(P>0.05)$. Eventually, the overall duration of stay after the procedure was shorter in the HIPEC group (8.15 versus 14.08 days, $P<0.05)$.

\section{Survival analysis}

During a median follow-up of 32 months, 4/80 died of disease progression (1 patient from each group died of brain metastasis undetected at presentation and 1 patient from each group died of extensive metastasis). At 3 years of follow up, from the HIPEC group, there were 3/40 cases of disease progression ( 1 case of brain metastasis at 6 months, 1 case of extensive with peritoneal metastasis at 14 months and 1 case of retroperitoneal lymph node metastasis at 18 months); in the Control group, there were $14 / 40$ cases of disease progression (4 cases presented with liver metastasis with possible peritoneal dissemination at 19, 14, 12 and 13 months; 5 cases of peritoneal metastasis at $9,12,14,15,17$ months; 1 case of brain metastasis at 11 months; 1 case of extensive metastasis at 14 months; 3 cases with retroperitoneal lymph node metastasis at 14 , 16, 20 months) and the difference in the disease free survival (DFS) was statistically significant (93\% vs $65 \%$, $P=0.0054$ ) (see Fig. 2). The peritoneal recurrence rate of the control group was much higher than the HIPEC group (3\% vs $23 \%, P<0.05)$.

\section{Discussion}

The mortality rate after intraoperative HIPEC has been reported to be ranging from 0.9 to $5.8 \%$ [24]. Recent studies showed that perioperative hypothermia manifests in more than $70 \%$ of patients and eventually can lead to several complications such as augmented intraoperative blood loss due to impaired platelet function and clotting factor enzyme function, peripheral vasoconstriction increasing the incidence of surgical wound infection due to reduction of subcutaneous oxygen tension and an impairment in immune function, or increase in heart rate and oxygen demand in the presence of shivering [25-29]. Therefore, thermoregulation plays a very important role during the HIPEC procedure. Nevertheless, the risks associated with hyperthermia have also been linked with direct complications on the gastrointestinal and cardiovascular functions. Significant fluctuations in the temperature during the procedure could lead to dangerous outcomes such as intestinal necrosis, hemorrhage, renal and hepatic dysfunctions and in case of intracranial hyperthermia, there could be cognitive impairments which could lead to electrophysiological alterations. In this study, we monitored the changes in 
Table 3 Comparison of blood and intracranial temperatures during the HIPEC procedure

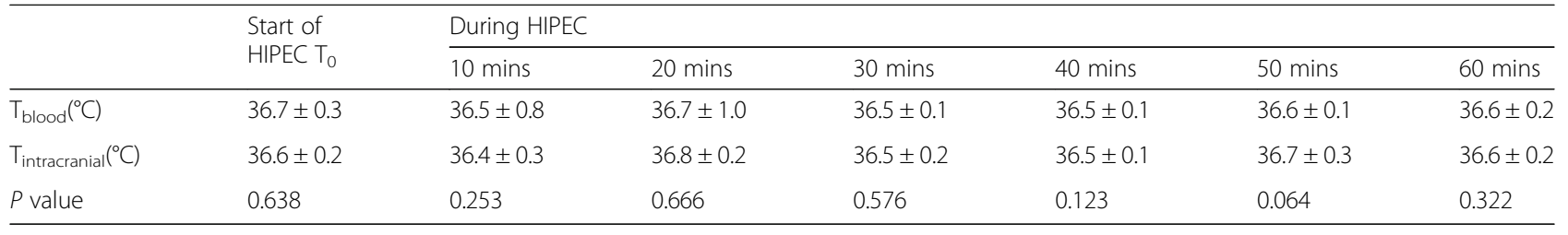

the intraperitoneal, blood and intracranial temperatures of the HIPEC patients when the target therapeutic intraperitoneal temperature was set to $42.0^{\circ} \mathrm{C}$ and the results showed no significant difference found in the three correlated sets temperatures, suggesting that the continuous flow during the HIPEC procedure not only allowed stable hyperthermia in the peritoneal cavity but simultaneously decreased the risks of hyperthermia in the peripheral blood and intracranial environment. In contrast, while monitoring the daily temperatures of the 80 subjects within one week after the procedure, no significant different was recorded in the overall trend between the 2 sets of patients, suggesting that the application of HIPEC did not contribute to post-operative fever or related morbidity.

HIPEC has also been associated with postoperative fever, severe local and/or systemic infection, intestinal or anastomotic leakage, intestinal obstruction, hemorrhage, HIPEC-related peritonitis, myelosuppression etc. Literature reports about $40 \%$ of patients developing at least one postoperative in hospital complication [30] with a low incidence of need for organ support and other significant critical care interventions [31]. Previous research have recognized some rather common procedure-related complications such as anastomotic leaks (0-9\%), intra-abdominal abscesses (0-37\%), intestinal perforation (0-10\%), fistulas (0-23\%), and prolonged ileus (0-86\%) [15-17]. Nevertheless, other morbidity such as post-operative bleeding, bile leaks, pancreatitis, wound infections, acalculous cholecystitis, mesenteric ischemia, mechanical intestinal obstruction have also been reported, but with lower incidence rate [16-20]. However, in our study, there was no incidence of these complications and when compared to the control group, the post-operative morbidity rate was not found to be statistically different, further affirming that HIPEC is not a significant risk factor associated with postoperative complications. We did not record any HIPEC related mortality in our study.

The HIPEC patients showed relatively faster gastrointestinal function recovery with flatus or passing of stool at around $42.9 \mathrm{~h}$ post-operatively (compared to $67.8 \mathrm{~h}$ in the control group). They were hence started on liquid diets earlier than the control group. The HIPEC patients did not complain of any episodes of intestinal cramps or abdominal discomfort after the surgery while the control group patients complained about intermittent intestinal cramps that subsided after passing gas. The time to suture removal was also 7 to 8 days in both groups, suggesting that the hyperthermia during the surgery had not compromised with the healing process of both the incision and anastomosis. Moreover, the overall duration of stay after the procedure was shorter in the HIPEC group (8.2 versus 14.1 days, $P<0.05)$. These results suggest that the patients undergoing HIPEC had quicker postoperative recovery with comparably lower incidence of postoperative complications.

The perioperative clinical management of AGC patients with high risk of intraperitoneal dissemination requires the prophylactic curative effect of HIPEC. In this study, we have assessed the various aspects of the safety issues that were initially linked with the routine practice of HIPEC and we have concluded that based on a randomized controlled approach, the combination of CS and HIPEC was efficient, safe and less risky as proposed in previous literature. Currently, there are few meta-analyses overviewing the outcomes of previous trials using prophylactic HIPEC [32-36] among which 2 meta-analyses included only patients receiving HIPEC in the experimental arm [18,37] and both of them did not show any significant increase in the rate of postoperative morbidity.

In this study, we have conducted a short term DFS investigation and out results concluded that from the

Table 4 Post-operative maximum daily temperatures of all the 80 subjects

\begin{tabular}{|c|c|c|c|c|c|c|c|}
\hline & \multicolumn{7}{|c|}{ Post-operative Maximum Body Temperature $\left({ }^{\circ} \mathrm{C}\right)$} \\
\hline & Day 1 & Day 2 & Day 3 & Day 4 & Day 5 & Day 6 & Day 7 \\
\hline HIPEC Group $(n=40)$ & $36.8 \pm 0.4$ & $36.7 \pm 0.3$ & $36.8 \pm 1.6$ & $36.8 \pm 0.2$ & $36.6 \pm 0.2$ & $36.7 \pm 1.3$ & $36.8 \pm 0.2$ \\
\hline Control Group $(n=40)$ & $37.7 \pm 0.6$ & $37.2 \pm 0.2$ & $36.9 \pm 0.2$ & $36.9 \pm 0.2$ & $36.8 \pm 0.3$ & $36.7 \pm 0.2$ & $36.7 \pm 0.2$ \\
\hline$P$ value & 0.001 & 0 & 0.404 & 0.638 & 0.572 & 0.129 & 0.176 \\
\hline
\end{tabular}


Table 5 Comparison of the post-operative blood physiological and biochemical parameters of the HIPEC and control groups

\begin{tabular}{|c|c|c|c|c|c|}
\hline Parameters & Groups & Day 1 & Day 3 & Day 7 & Day 30 \\
\hline \multirow[t]{3}{*}{$\overline{W B C}\left(10^{9} / L\right)$} & HIPEC $(n=40)$ & $14.01 \pm 3.45$ & $7.11 \pm 2.51$ & $6.08 \pm 1.61$ & $4.97 \pm 1.23$ \\
\hline & Control $(n=40)$ & $13.34 \pm 2.41$ & $7.03 \pm 2.13$ & $5.88 \pm 1.46$ & $4.86 \pm 1.39$ \\
\hline & $P$ Value & 0.09 & 0.25 & 0.538 & 0.823 \\
\hline \multirow[t]{3}{*}{$\mathrm{RBC}\left(10^{12} / \mathrm{L}\right)$} & $\operatorname{HIPEC}(n=40)$ & $4.07 \pm 0.54$ & $3.87 \pm 0.63$ & $3.99 \pm 0.55$ & $4.05 \pm 0.51$ \\
\hline & Control $(n=40)$ & $4.24 \pm 0.47$ & $4.01 \pm 0.56$ & $3.94 \pm 0.49$ & $4.03 \pm 0.52$ \\
\hline & $P$ Value & 0.943 & 0.08 & 0.252 & 0.854 \\
\hline \multirow[t]{3}{*}{$\mathrm{Hb}(\mathrm{g} / \mathrm{L})$} & $\operatorname{HIPEC}(n=40)$ & $121.60 \pm 7.37$ & $118.05 \pm 19.59$ & $125.08 \pm 12.11$ & $121.50 \pm 22.12$ \\
\hline & Control $(n=40)$ & $123.53 \pm 17.54$ & $116.88 \pm 19.69$ & $114.95 \pm 16.82$ & $128.30 \pm 12.43$ \\
\hline & $P$ Value & 0.899 & 0.1 & 0.518 & 0.335 \\
\hline \multirow[t]{3}{*}{ Alb (g/L) } & HIPEC $(n=40)$ & $30.93 \pm 3.33$ & $37.68 \pm 4.07$ & $38.65 \pm 4.86$ & $18.80 \pm 8.33$ \\
\hline & Control $(n=40)$ & $31.28 \pm 3.43$ & $36.33 \pm 6.25$ & $39.92 \pm 7.38$ & $19.25 \pm 8.00$ \\
\hline & $P$ Value & 0.6 & 0.86 & 0.323 & 0.640 \\
\hline \multirow[t]{3}{*}{ AST (IU/L) } & $\operatorname{HIPEC}(n=40)$ & $21.33 \pm 10.49$ & $28.95 \pm 9.92$ & $20.15 \pm 11.1$ & $21.28 \pm 3.06$ \\
\hline & Control $(n=40)$ & $22.98 \pm 9.25$ & $27.42 \pm 11.45$ & $21.2 \pm 16.07$ & $21.62 \pm 2.78$ \\
\hline & $P$ Value & 0.09 & 0.111 & 0.347 & 0.759 \\
\hline \multirow[t]{3}{*}{ ALT (IU/L) } & $\operatorname{HIPEC}(n=40)$ & $34.85 \pm 19.8$ & $26.38 \pm 16.15$ & $21.03 \pm 10.49$ & $21.30 \pm 6.47$ \\
\hline & Control $(n=40)$ & $29.53 \pm 20.05$ & $19.92 \pm 15.10$ & $22.98 \pm 17.9$ & $21.32 \pm 7.34$ \\
\hline & $P$ Value & 0.154 & 0.1 & 0.149 & 0.786 \\
\hline \multirow[t]{3}{*}{ TB (umol/L) } & $\operatorname{HIPEC}(n=40)$ & $16.24 \pm 4.59$ & $16.19 \pm 5.42$ & $15.75 \pm 5.43$ & $11.73 \pm 4.13$ \\
\hline & Control $(n=40)$ & $12.91 \pm 3.85$ & $17.07 \pm 0.88$ & $17.01 \pm 8.03$ & $12.64 \pm 2.83$ \\
\hline & $P$ Value & 0.456 & 0.242 & 0.121 & 0.71 \\
\hline \multirow[t]{3}{*}{ DB (umol/L) } & $\operatorname{HIPEC}(n=40)$ & $3.72 \pm 1.73$ & $3.11 \pm 1.69$ & $3.48 \pm 1.80$ & $2.27 \pm 1.18$ \\
\hline & Control $(n=40)$ & $3.64 \pm 1.51$ & $3.45 \pm 0.91$ & $3.12 \pm 2.12$ & $2.75 \pm 1.02$ \\
\hline & $P$ Value & 0.511 & 0.84 & 0.902 & 0.931 \\
\hline \multirow[t]{3}{*}{ SCr (umol/L) } & $\operatorname{HIPEC}(n=40)$ & $70.62 \pm 27.1$ & $68.13 \pm 14.6$ & $71.05 \pm 17.93$ & $68.42 \pm 16.42$ \\
\hline & Control $(n=40)$ & $72.37 \pm 25.4$ & $63.31 \pm 18.1$ & $64.54 \pm 13.69$ & $67.27 \pm 12.9$ \\
\hline & $P$ Value & 0.319 & 0.569 & 0.199 & 0.09 \\
\hline \multirow[t]{3}{*}{$\mathrm{K}+(\mathrm{mmol} / \mathrm{L})$} & $\operatorname{HIPEC}(n=40)$ & $3.66 \pm 0.49$ & $3.62 \pm 0.52$ & $3.85 \pm 0.23$ & $3.64 \pm 0.19$ \\
\hline & Control $(n=40)$ & $3.69 \pm 0.39$ & $3.92 \pm 0.51$ & $3.81 \pm 0.39$ & $3.78 \pm 0.21$ \\
\hline & $P$ Value & 0.89 & 0.763 & 0.743 & 0.452 \\
\hline \multirow[t]{3}{*}{$\mathrm{Na}+(\mathrm{mmol} / \mathrm{L})$} & $\operatorname{HIPEC}(n=40)$ & $137.23 \pm 2.89$ & $139.28 \pm 2.97$ & $138.57 \pm 2.54$ & $139.12 \pm 1.89$ \\
\hline & Control $(n=40)$ & $137.25 \pm 2.62$ & $141.25 \pm 1.63$ & $138.25 \pm 2.34$ & $138.82 \pm 1.97$ \\
\hline & $P$ Value & 0.924 & 0.897 & 0.824 & 0.813 \\
\hline
\end{tabular}

WBC White Blood Cell Count, RBC Red Blood Cell Count, Hb Hemoglobin, Alb Albumin, AST Aspartate Aminotransferase, ALT Alanine transaminase, TB Total Bilirubin, DB Direct Bilirubin, SCr Serum Creatinine, $K+$ Potassium lon, Na+ Sodium lon

HIPEC group, there were $4 / 40$ cases of disease progression $(1$ case of brain metastasis at 6 months, 1 case of extensive metastasis at 12 months, 1 case of liver metastasis at 14 months and 1 case of retroperitoneal lymph node metastasis at 18 months); in the non-HIPEC group, there were $14 / 40$ cases of disease progression (4 cases presented with liver metastasis with possible peritoneal dissemination at 19,14, 12 and 13 months; 5 cases of peritoneal metastasis at 9, 12, 14, 15, 17 months; 1 case of brain metastasis at 11 months; 1 case of extensive metastasis at 14 months; 3 cases with retroperitoneal lymph node metastasis at 14, 16, 20 months) and the difference in the disease free survival (DFS) was statistically significant $(P=0.0016)$. The peritoneal recurrence rate of the control group was higher than the HIPEC group $(P<0.05)$., suggesting that Intraoperative HIPEC can effectively improve the survival outcome of advanced GC patients at risk of peritoneal dissemination and decrease the rate of peritoneal recurrence. 
Table 6 Most common grade 3-5 adverse events and adverse events of special interest with cisplatin (related and unrelated events; safety population); Results are presented as number of patients and all the side-effects were evaluated according to CTCAE v4.0

\begin{tabular}{lll}
\hline Complication & $\begin{array}{l}\text { HIPEC Group } \\
(n=40)\end{array}$ & $\begin{array}{l}\text { Control Group } \\
(n=40)\end{array}$ \\
\hline Neutropenia & 1 & 2 \\
Anastomotic Leak & 0 & 1 \\
Bowel Obstruction & 0 & 1 \\
Renal Toxicity & 1 & 1 \\
Liver Function Dysfunction & 0 & 2 \\
Hyperbilirubinemia & 1 & 2 \\
Post-operative Infection & 0 & 1 \\
Surgical Wound Dehiscence & 0 & 1 \\
Total Perioperative Side-effects & 3 & 11 \\
\hline
\end{tabular}

In an overview of 10 RCTs, Sun et al. [18] suggested a significant advantage in survival with the use of HIPEC. In contrast, while investigating 16 RCTs, Mi et al. [37] reported a significant improvement in the 1, 2, 3, 5 and 9 -year survival and a decrease in the peritoneal recurrence rates at 2, 3 and 5 years in patients who received HIPEC.

There were 2 mortalities recorded in our study, both patients developing brain metastasis during the follow-up period. Of the 40 patients from the control group, 6 patients had disease progression with 4 patients presenting with liver metastasis with possible peritoneal metastasis and the other 2 with retroperitoneal lymphadenopathy with peritoneal metastasis. The HIPEC group patients are still stable. The median time to disease progression was around 13 months, which is consistent with previous literature. There have been speculations about the high concentration of hyperthermic drugs in the abdominal cavity facilitated the absorption by the peritoneum and the circulatory system through the portal vein and retroperitoneal lymphatic system, which is very consistent with route of GC metastasis, therefore controlling micro-metastases in the lymphatic system and liver [38]. However, more concrete evidence is required to sustain this hypothesis.

\section{Limitations of the study}

This study has been presented in the form of an observational study due to its limitations as a fully structured randomized controlled trial. In this study, we have tried to investigate the feasibility and efficacy of HIPEC on consecutive 40 patients by comparing their outcomes with consecutive simultaneous 40 control subjects, all undergoing D2 radical gastrectomy. Our future prospects would be to follow-up the investigation with a larger and more structured prospective RCT approach.

\section{Conclusion}

The rising incidence of GC around the world prompts for comprehensive multimodality treatment plans in order to improve AGC prognosis. The combination of intraoperative HIPEC with CS offers better clinical management of patients with high risk of secondary peritoneal carcinomatosis, favoring their post-operative recovery at low incidence of complications and eventually improving their survival rates.

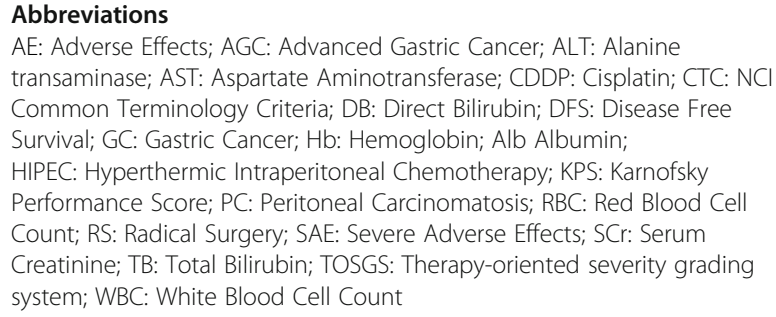

\section{Acknowledgements}

NA

\section{Authors' contributions}

BMK has designed, conducted, analyzed and drafted the manuscript. ZZL has supported the experiment design and implementation, provided essential guidance for the data analysis, LWT has provided guidance during the implementation and supported the follow-up analysis; YXX has provided overall guidance in the conception, development, implementation and analysis of the study and approved the manuscript. YM was one of the surgeons of the dedicated surgical panel to perform the surgery and provided professional guidance throughout the study. ZGG has provided professional guidance and was one of the surgeons of the dedicated surgical panel to perform the surgery and has supported the data and results of the manuscript. All authors have read and approved the final manuscript.

\section{Funding}

No funding.

Availability of data and materials

Data and material are available upon request.

\section{Ethics approval}

This study was approved by the Ethics committee of Ruilin Hospital affiliated Shanghai Jiao Tong University School of Medicine. All patients have provided written consent to participate in the study.

\section{Consent for publication}

All the participants have written consent to participate and publish the data.

\section{Competing interests}

The authors declare that they have no competing interests.

Received: 2 March 2019 Accepted: 3 September 2019

Published online: 18 September 2019

\section{References}

1. Ferlay J, Soerjomataram I, Dikshit R, et al. Cancer incidence and mortality worldwide: sources, methods and major patterns in GLOBOCAN 2012. Int J Cancer. 2015;136(5):E359-86.

2. Bieri U, Moch H, Dehler S, Korol D, Rohrmann S. Changes in autopsy rates among cancer patients and their impact on cancer statistics from a public health point of view: a longitudinal study from 1980 to 2010 with data from 
Cancer registry Zurich. Virchows Arch. 2015;466:637-43. https://doi.org/10. 1007/s00428-015-1734-7.

3. Berretta M, Fisichella R, Borsatti E, et al. Feasibility of intraperitoneal Trastuzumab treatment in a patient with peritoneal carcinomatosis from gastric cancer. Eur Rev Med PharmacolSci. 2014;18:689-92 [PubMed].

4. Bozzetti F, Yu W, Baratti D, Kusamura S, Deraco M. Locoregional treatment of peritoneal carcinomatosis from gastric cancer. J SurgOncol. 2008;98:273-6 CrossRefMedlineGoogle Scholar.

5. Okajima K, Yamada S. Surgical treatment of far-advanced gastric cancer. Jpn J Cancer Clin. 1986;32:1203-9 Google Scholar.

6. Chu DZ, Lang NP, Thompson C, Osteen PK, Westbrook KC. Peritoneal carcinomatosis in non-gynecologic malignancy. A prospective study of prognostic factors. Cancer. 1989;63:364-7 CrossRefMedlineGoogle Scholar.

7. Yamada S, Takeda T, Matsumoto K. Prognostic analysis of malignant pleural and peritoneal effusions. Cancer. 1983;51:136-40 MedlineGoogle Scholar.

8. Sadeghi B, Arvieux C, Glehen O, Beaujard AC, Rivoire M, Baulieux J, Fontaumard E, Brachet A, Caillot JL, Faure JL, Porcheron J, Peix JL, Franç̧ois Y, Vignal J, Gilly FN. Peritoneal carcinomatosis from non-gynecologic malignancies: results of the EVOCAPE 1 multicenter prospective study. Cancer. 2000;88:358-63 CrossRefMedlineGoogle Scholar.

9. Kang H, Kauh JS. Chemotherapy in the treatment of metastatic gastric cancer: is there a global standard? Curr Treat Options Oncol. 2011;12:96-106 CrossRefMedlineGoogle Scholar.

10. Yonemura Y, Fujimura T, Nishimura G, Falla R, Sawa T, Katayama K, Tsugawa K, Fushida S, Miyazaki I, Tanaka M, Endou Y, Sasaki T. Effects of intraoperative chemo-hyperthermia in patients with gatsric cancer with periotneal dissemination. Surgery. 1996;119:437-44 CrossRefMedlineGoogle Scholar.

11. Seyfried F, von Rahden BH, Miras AD, et al. Incidence, time course and independent risk factors for metachronous peritoneal carcinomatosis of gastric origin--a longitudinal experience from a prospectively collected database of 1108 patients. BMC Cancer. 2015;15:73. https://doi.org/10.1186/ s12885-015-1081-8.

12. Japanese Research Society for Gastric Cancer. The general rules for gastric Cancer study. 1st ed. Tokyo, Japan: Kanahara Shuppan; 1995.

13. Bando $E$, Yonemura $Y$, Takeshita $Y$, et al. Intraoperative lavage for cytological examination in 1,297 patients with gastric carcinoma. Am J Surg. 1999;178: 256-62. https://doi.org/10.1016/S0002-9610(99)00162-2.

14. Coccolini F, Cotte E, Glehen O, et al. Intraperitoneal chemotherapy in advanced gastric cancer. Meta-analysis of randomized trials. Eur J Surg Oncol. 2014;40:12-26. https://doi.org/10.1016/j.ejso.2013.10.019.

15. Vanounou T, Garfinkle R. Evaluation of Cytoreductive surgery and Hyperthermic intraperitoneal chemotherapy for peritoneal Carcinomatosis of colorectal origin in the era of value-based medicine. Ann Surg Oncol. 2016;23:2556-61. https://doi.org/10.1245/s10434-016-5096-4.

16. Huo YR, Richards A, Liauw W, Morris DL. Hyperthermic intraperitoneal chemotherapy (HIPEC) and cytoreductive surgery (CRS) in ovarian cancer: a systematic review and meta-analysis. Eur J Surg Oncol. 2015;41:1578-89. https://doi.org/10.1016/j.ejso.2015.08.172.

17. Kelly KJ, Nash GM. Peritoneal debulking/intraperitoneal chemotherapy-nonsarcoma. J Surg Oncol. 2014;109:14-22. https://doi.org/10.1002/jso.23449.

18. Sun J, Song $Y$, Wang $Z$, et al. Benefits of hyperthermic intraperitoneal chemotherapy for patients with serosal invasion in gastric cancer: a metaanalysis of the randomized controlled trials. BMC Cancer. 2012;12:526. https://doi.org/10.1186/1471-2407-12-526.

19. Zhu ZG, Tang R, Yan M, Chen J, Yang QM, Li C, Yao XX, Zhang J, Yin HR, Lin $Y Z$. Efficacy and safety of intraoperative peritoneal hyperthermic chemotherapy for advanced gastric cancer patients with serosal invasion. A long-term follow-up study. Dig Surg. 2006;23(1-2):93-102.

20. Fujimura $T$, Yonemura $Y$, Nakagawara $H$, et al. Subtotal peritonectomy with chemohyperthermic peritoneal perfusion for peritonitis carcinomatosa in gastrointestinal cancer. Oncol Rep. 2000;7:809-14.

21. Gill RS, Al-Adra DP, Nagendran J, et al. Treatment of gastric cancer with peritoneal carcinomatosis by cytoreductive surgery and HIPEC: a systematic review of survival, mortality, and morbidity. J Surg Oncol. 2011;104:692-8. https://doi.org/10.1002/jso.22017.

22. Yan TD, Deraco M, Baratti D, et al. Cytoreductive surgery and hyperthermic intraperitoneal chemotherapy for malignant peritoneal mesothelioma: multi-institutional experience. J Clin Oncol. 2009;27:6237-42.

23. Desiderio J, Chao J, Melstrom L, et al. The Thirty-Year Experience - A Metaanalysis of Randomized and High Quality Non-Randomized Studies of Hyperthermic Intraperitoneal Chemotherapy (HIPEC) in the Treatment of
Gastric Cancer. Eur J Cancer (Oxford, England : 1990). 2017;79:1-14. https:// doi.org/10.1016/j.ejca.2017.03.030

24. Dindo D, Demartines N, Clavien PA. Classification of surgical complications: a new proposal with evaluation in a cohort of 6336 patients and results of a survey. Ann Surg. 2004;240(2):205-13.

25. Kajdi ME, Beck-Schimmer B, Held U, Kofmehl R, Lehmann K, Ganter MT. Anaesthesia in patients undergoing cytoreductive surgery with hyperthermic intraperitoneal chemotherapy: retrospective analysis of a single centre three-year experience. World J SurgOncol. 2014;12:136. https:// doi.org/10.1186/1477-7819-12-136.

26. Albertsmeier M, Hauer A, Niess H, Werner J, Graeb C, Angele MK. Quality of life in peritoneal carcinomatosis. a prospective study in patients undergoing cytoreductive surgery and hyperthermic intraperitoneal chemotherapy (HIPEC). Dig Surg. 2014;31 (4-5):334-40.

27. Kerscher C, Ried M, Hofmann HS, Graf BM, Zausig YA. Anaesthetic management of cytoreductive surgery followed by hyperthermic intrathoracic chemotherapy perfusion. J CardiothoracSurg. 2014;9:125.

28. Cooksley TJ, Haji-Michael P. Post-operative critical care management of patients undergoing cytoreductive surgery and heated intraperitoneal chemotherapy (HIPEC). World J SurgOncol. 2011;9:169.

29. Hakeam HA, Breakiet M, Azzam A, Nadeem A, Amin T. The incidence of cisplatin nephrotoxicity post hyperthermic intraperitoneal chemotherapy (HIPEC) and cytoreductive surgery. Ren Fail. 2014;36(10):1486-91.

30. Iversen LH, Rasmussen PC, Hagemann-Madsen R, Laurberg S. Cytoreductive surgery and hyperthermic intraperitoneal chemotherapy for peritoneal carcinomatosis: the Danish experience. Color Dis. 2013;15(7):e365-72.

31. Rossaint R, Bouillon B, Cerny V, et al. Task force for advanced bleeding care in trauma. Management of bleeding following major trauma: an updated European guideline. Crit Care. 2010;14(2):R52.

32. Sugarbaker PH, Yu W, Yonemura Y. Gastrectomy, peritonectomy, and perioperative intraperitoneal chemotherapy: the evolution of treatment strategies for advanced gastric cancer. SeminSurgOncol. 2003;21:233-48.

33. Yan TD, Black D, Sugarbaker PH, Zhu J, Yonemura Y, Petrou G, Morris DL. A systematic review and meta-analysis of the randomized controlled trials on adjuvant intraperitoneal chemotherapy for resectable gastric cancer. AnnSurgOncol. 2007;14:2702-13.

34. Huang JY, XU YY, Sun Z, Zhu Z, Song YX, Guo PT, You Y, Xu HM. Comparison different methods of intraoperative and intraperitoneal chemotherapy for patients with gastric cancer: a meta-analysis. Asian Pac J Cancer Prev. 2012;13:4379-85.

35. Coccolini F, Cotte E, Glehen O, Lotti M, Poiasina E, Catena F, Yonemura Y, Ansaloni L. Intraperitoneal chemotherapy in advanced gastric cancer. Metaanalysis of randomized trials. Eur J SurgOncol. 2014;40:12-26.

36. Xu DZ, Zhan YQ, Sun XW, Cao SM, Geng QR. Meta-analysis of intraperitoneal chemotherapy for gastric cancer. World J Gastroenterol. 2004;10:2727-30.

37. Mi DH, Li Z, Yang KH, Cao N, Lethaby A, Tian JH, Santesso N, Ma B, Chen YL, Liu YL. Surgery combined with intraoperative hyperthermic intraperitoneal chemotherapy (IHIC) for gastric cancer: a systematic review and metaanalysis of randomised controlled trials. Int J Hyperth. 2013;29:156-67.

38. Padmanabhan N, Kumar BR, Pookunju AP, et al. Preliminary experience and morbidity analysis of Cytoreductive surgery with Hyperthermic intraperitoneal chemotherapy (CRS/HIPEC) from a tertiary Cancer Center in India. J ClinDiagn Res. 2015;9:XC09-13.

\section{Publisher's Note}

Springer Nature remains neutral with regard to jurisdictional claims in published maps and institutional affiliations. 